\title{
Temperature Dependence of Thermophysical Properties of Full-Scale Corium of Fast Energy Reactor
}

\author{
Mazhyn K. Skakov, ${ }^{1}$ Nurzhan Ye. Mukhamedov, ${ }^{2}$ \\ Alexander D. Vurim, ${ }^{1}$ and Ilya I. Deryavko ${ }^{1}$ \\ ${ }^{1}$ Institute of Atomic Energy, RSE NNC RK, Kurchatov 071100, Kazakhstan \\ ${ }^{2}$ Shakarim State University of Semey, Semey 071400, Kazakhstan \\ Correspondence should be addressed to Nurzhan Ye. Mukhamedov; mukhamedov@nnc.kz
}

Received 20 January 2017; Revised 1 March 2017; Accepted 27 March 2017; Published 12 June 2017

Academic Editor: Eugenijus Ušpuras

Copyright ( 2017 Mazhyn K. Skakov et al. This is an open access article distributed under the Creative Commons Attribution License, which permits unrestricted use, distribution, and reproduction in any medium, provided the original work is properly cited.

For the first time the paper determines thermophysical properties (specific heat capacity, thermal diffusivity, and heat conductivity) of the full-scale corium of the fast energy nuclear reactor within the temperature range from $\sim 30^{\circ} \mathrm{C}$ to $\sim 400^{\circ} \mathrm{C}$. Obtained data are to be used in temperature fields calculations during modeling the processes of corium melt retention inside of the fast reactor vessel.

\section{Introduction}

Research of thermophysical properties of the materials and fuel of nuclear reactor at high temperatures is an important scientific problem of practical relevance. From the practical point of view data of thermophysical properties of the melt reactor core (corium) and its individual components are important for modeling the phenomena and processes being an integral part of hypothetical nuclear reactors severe disasters scenarios.

It is known that thermophysical properties (TPP) of corium [1-4] got during the experiments simulating severe accidents in nuclear reactors are most important characteristics since the information about TPP is exclusively useful for revealing the mechanisms of severe reactor accidents. This is why it is necessary to study corium thermophysical properties experimentally to form database that can be used in computational models and to predict the way of severe accident.

As part of the above research, the Institute of Atomic Energy (IAE) NNC RK conducts experiments at the IGR research reactor to study behavior of fast energy nuclear reactor fuel under the conditions of severe accident with loss of coolant (LOCA).

The work is focused on experimentally determining TPP of full-scale corium (solidified mixture of uranium and steel dioxides) of fast energy reactor produced during one of such experiments at the IGR reactor.

\section{Material and Methods}

As an investigation material, an ingot of full-scale corium was obtained by irradiating an experimental device on an IGR reactor. The experimental device included a fuel assembly consisting of fuel pellets of uranium dioxide with enrichment of $17 \%$ at ${ }^{235} \mathrm{U}$ in the active part and $0.27 \%$ at ${ }^{235} \mathrm{U}$ in the blanket part. The fuel claddings were made of steel tubes Cr16Ni15Mo3Nb. Foreign analogues of Cr16Ni15Mo3Nb steel are 318 (USA) and X10CrNiMoNb18-12 (Germany).

Thermophysical properties of the obtained corium were measured on UTFI-2 laboratory installation. For determining TPP we used methodology in [5]. The main point of the methodology is heating one of the ends of the plane disc sample by short term exposure of heat pulse and registration of temporary dependence upon $T=f(\tau)$ temperature on the opposite sample end. We have used the measurement scheme with two samples one of which is a major (examined), and the other one is an auxiliary sample (Figure 1). We used a disk sample of sintered uranium dioxide as an auxiliary sample. Heat impulse was created by electric heater located between the researched and the auxiliary samples. 


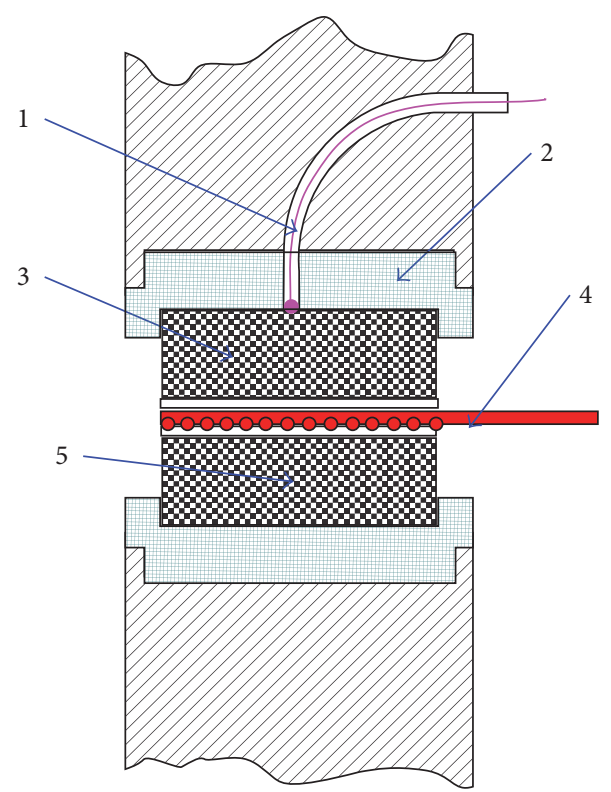

FIGURE 1: Scheme of placing samples in UTFI-2 installation: 1: thermocouple; 2: heat insulation; 3: examined sample; 4: heating element; 5: auxiliary sample.

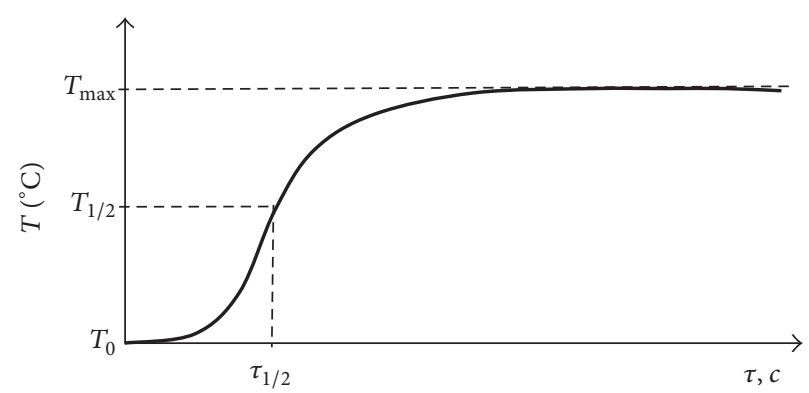

FIGURE 2: The typical form of changing temperature fixed on the sample back surface.

Using this methodology it is necessary to obtain (Figure 2) thermogram and with its help determine such sample parameters as $\Delta T$ overheat (the difference between the sample initial and maximum temperatures) and $\tau_{1 / 2}$ is the time of reaching half of the sample surface maximum temperature. These parameters allow calculating target value of such sample TPP as $a$, thermal diffusivity, $C_{p}$, specific heat capacity, and $\lambda$, heat conduction.

Research on structure and elemental composition of corium was conducted on JSM-6390 raster-electron microscope of JEOL Japan company equipped by JED-2300 energo dispersive microscope.

X-ray structural corium researches were conducted on Empyrean diffractometer with Rentgen-Master controlling computer system using $\mathrm{CuK}_{\alpha}$-radiation.

$\mathrm{X}$-rayograms were obtained by monochromated $\mathrm{CuK} \alpha$ radiation $\left(\lambda_{\mathrm{K} \alpha 1}=0.154056 \mathrm{~nm}\right)$ under accelerating voltage of $20 \mathrm{kV}$ and anode current of $40 \mathrm{~mA}$ with scanning interval with angle of $2 \theta: 30^{\circ}-120^{\circ}$ and stride of $0.02^{\circ}$.

$\mathrm{X}$-rayogram transcript was carried out by Crystallography Open Database (COD). Quantity analysis was conducted by HighScore software. Presence of one or another phase was fixed if two more intensive lines were marked in X-rayogram.

\section{Results and Discussion}

Diffractogram analysis from sample surface detected uranium dioxide with face centered cubic lattice with evaluative parameter of lattice $a=0.547 \mathrm{~nm}$ ( $\sim 99 \%$ on mass) as main crystal phase.

On diffractograms of all samples main phase peaks are tight, with permitted $K \alpha_{1,2}$ doublet. The ratio of phase line intensity of all samples differs markedly from the ratio of lines intensity of this phase in database, indicating the presence of crystallite preferred orientation on samples.

The result of research of light line intensity was the detection of phase line on the basis of $\alpha$-(Fe, $\mathrm{Ni}, \mathrm{Cr}$ ) ferrite. Fraction of metal contaminations in samples according to microstructure research results was at a level of $1.5-2.5 \%$, and there was no considerable dispersion of fraction on sample surface. Elemental composition of contamination shows that main elements of its chemical composition are components of chrome-nickel stainless steel in decreasing order of $\mathrm{Fe}, \mathrm{Cr}$, $\mathrm{Ni}, \mathrm{Mo}$, and Mn.

Sample surfaces structure is characterized by pore and fracture presence. There was large amount of fracture in samples, forming fracture network among them (Figure 3). 


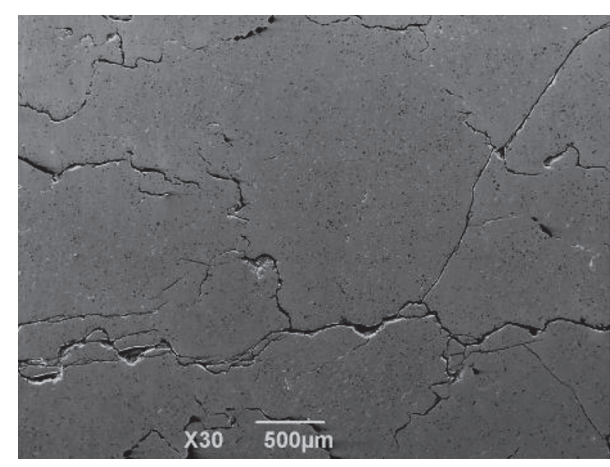

(a) Sample 1

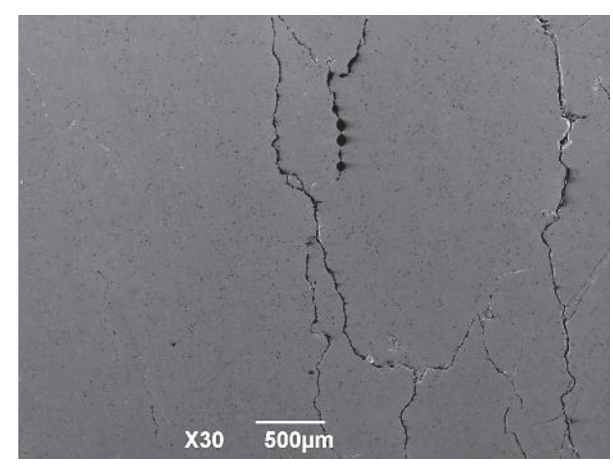

(b) Sample 2

FiguRE 3: Surface structure cut from solidified melt.

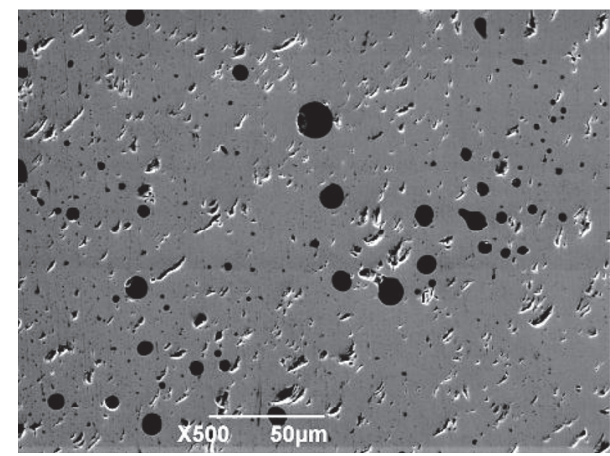

(a) Sample 1

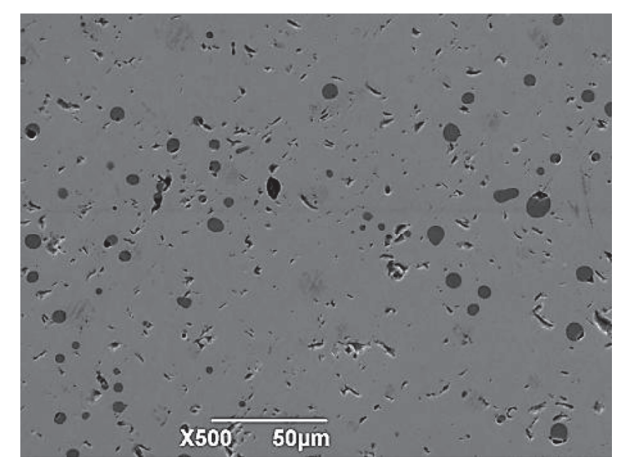

(b) Sample 2

FIGURE 4: Metallic contaminations in sample microstructure on magnification of $\times 500$.

During sample microstructure research, metallic contaminations with dimensions of $2-8 \mu \mathrm{m}$ were detected (Figure 4 ), distribution characters of which are at different marks of solidified melt.

EDS analysis of each sample was carried out for elemental composition of solidified melt. Data on elemental composition in mass and atom per cents were shown in Tables 1 and 2.

Local elemental analysis was conducted for identification of elemental composition of metallic contaminations (Figure 5 and Table 3 ).

Therefore, it was determined by local elemental analysis of metallic contaminations that contaminations predominantly consist of chrome and iron, and in this regard uranium content was about $1 \%$.

Table 4 shows the results of measuring diameter $d$, thickness $l$, mass $m$, determining density $\rho$, and porosity $\varepsilon$ of the samples material used in the measurements.

Uranium dioxide TPP calibration measurements were done before the corium TPP measurements. Table 5 shows the results of calibration measurements of the $\mathrm{UO}_{2}$ sample TPP inside the chamber.

Calibration measurements results have shown the correspondence within the error of measured TPP values defined under the working chamber conditions. Values obtained in the working chamber were taken as the basic ones for correction coefficient calculating. Table 6 shows the reference values taken for the calculation and the coefficients calculating results. Table 7 shows results of calculating correction coefficients using reference data [6].

Table 8 shows the results of TPP measurements of corium sample number 1 conducted during the measurements within the selected temperature range. The table shows the data taking into consideration the correction coefficients.

Results of TPP measurements of sample number 1 are well reproduced in the range of temperatures from $30^{\circ} \mathrm{C}$ to $300^{\circ} \mathrm{C}$ in the first cycle and during the heating in the second cycle.

At the same time thermophysical properties dependence deviations became more significant after heating up to $400^{\circ} \mathrm{C}$. Foremost, the thermal diffusivity values underwent changes. Thus, at the temperature of $100^{\circ} \mathrm{C}$, thermal diffusivity in the second-cycle control measurements was decreased on 5\%, heat capacity was increased on $2 \%$, and heat conductivity was decreased on $4 \%$.

Additional cycle of heating-cooling up to $400^{\circ} \mathrm{C}$ was conducted for checking the assumption about the beginning of structural changes of the corium material due to heating. In the process of heating at control temperatures of $200^{\circ} \mathrm{C}$ and $400^{\circ} \mathrm{C}$, samples were aged for an hour to reveal possible TPP changes with the course of time. Table 8 shows the measurement results. 


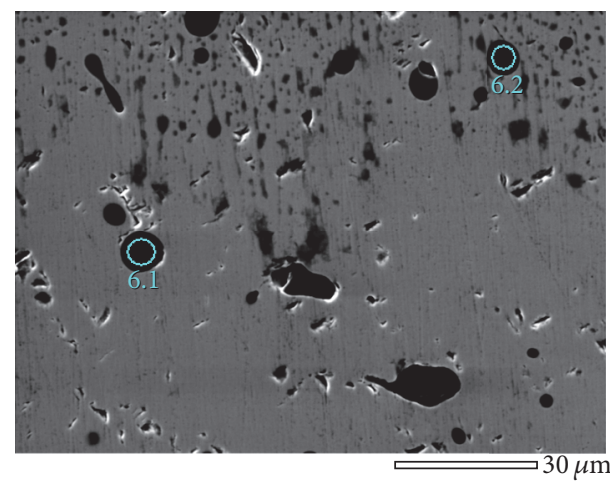

(a) Sample 1

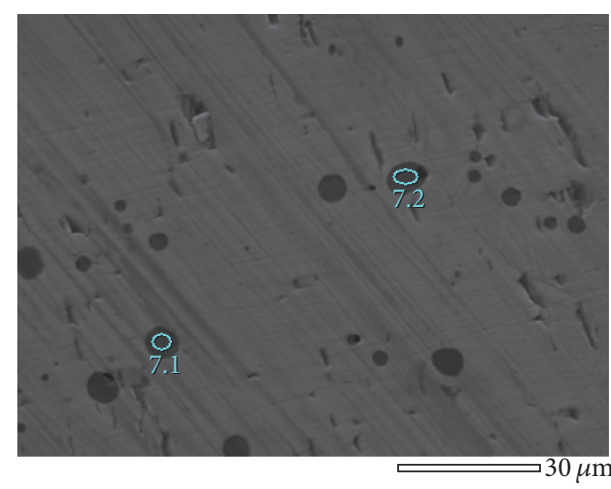

(b) Sample 2

FIGURE 5: Local elemental analysis of metallic contaminations.

TABLE 1: Elemental composition of researched sample surface in mass \%.

\begin{tabular}{lcccccccc}
\hline Samples & $\mathrm{U}$ & $\mathrm{Fe}$ & $\mathrm{Cr}$ & $\mathrm{O}$ & $\mathrm{Al}$ & $\mathrm{Ni}$ & $\mathrm{Ti}$ \\
\hline 1 & 86.86 & 0.84 & 0.95 & 9.89 & 1.24 & 0.14 & 0.07 \\
2 & 86.70 & 0.89 & 1.03 & 9.90 & 1.24 & 0.16 & 0.07 & 0.01 \\
\hline
\end{tabular}

TABLE 2: Elemental composition of researched sample surface in atom \%.

\begin{tabular}{lcccccccc}
\hline Samples & $\mathrm{U}$ & $\mathrm{Fe}$ & $\mathrm{Cr}$ & $\mathrm{O}$ & $\mathrm{Al}$ & $\mathrm{Ni}$ & $\mathrm{Ti}$ & $\mathrm{Nb}$ \\
\hline 1 & 34.22 & 1.42 & 1.72 & 57.98 & 4.30 & 0.23 & 0.14 & - \\
2 & 34.08 & 1.49 & 1.85 & 57.88 & 4.30 & 0.25 & 0.14 & 0.01 \\
\hline
\end{tabular}

TABLE 3: Elemental composition of metallic contaminations on samples, mass \%.

\begin{tabular}{lcccccccc}
\hline Analysis area & $\mathrm{O}$ & $\mathrm{Al}$ & $\mathrm{Ti}$ & $\mathrm{Cr}$ & $\mathrm{Fe}$ & $\mathrm{Ni}$ & $\mathrm{Nb}$ & - \\
\hline 6.1 & - & 1.04 & 0.87 & 62.04 & 30.39 & 3.73 & 1.93 \\
6.2 & 0.43 & 0.86 & 0.66 & 52.25 & 38.97 & 5.42 & 0.23 & 1.18 \\
7.1 & - & 0.62 & 0.19 & 29.67 & 61.47 & 6.25 & 0.68 \\
7.2 & - & 0.86 & 0.49 & 48.70 & 45.02 & 4.92 & - & 0.12 \\
\hline
\end{tabular}

TABLE 4: Results of sample parameter measurements.

\begin{tabular}{|c|c|c|c|c|c|}
\hline Sample & $l, \mathrm{~mm}$ & $d, \mathrm{~mm}$ & $m, \mathrm{~g}$ & $\rho, \mathrm{g} / \mathrm{cm}^{3}$ & $\varepsilon, \%$ \\
\hline Number 1 & $4.08 \pm 0.01$ & $10.77 \pm 0.10$ & $3.822 \pm 0.001$ & $10.3 \pm 0.19$ & $6 \pm 1.7$ \\
\hline Number 2 & $4.11 \pm 0.01$ & $10.89 \pm 0.07$ & $3.981 \pm 0.001$ & $10.4 \pm 0.16$ & $5 \pm 1.4$ \\
\hline $\mathrm{UO}_{2}$ & $4.02 \pm 0.01$ & $10.97 \pm 0.07$ & $3.8715 \pm 0.0001$ & $10.37 \pm 0.04$ & $5 \pm 1.4$ \\
\hline
\end{tabular}

TABLE 5: The result of uranium dioxide sample measurements.

\begin{tabular}{lcc}
\hline$a, 10^{-6} \mathrm{~m}^{2} / \mathrm{sec}$ & $C_{p}, \mathrm{~J} /(\mathrm{kg} \cdot \mathrm{K})$ & $\lambda, \mathrm{W} /(\mathrm{m} \cdot \mathrm{K})$ \\
\hline $2.413 \pm 0.003$ & $270 \pm 1.0$ & $6.69 \pm 0.02$ \\
\hline
\end{tabular}

Obtained coefficients values during the heating and cooling coincided quite accurately and practically reproduced the temperature dependence obtained during the cooling stage in the second heating cycle.

Table 9 shows the results of TPP measurements of corium sample number 2 conducted during the measurements within the selected temperature range. The table shows the data taking into consideration the correction coefficients.
Results of TPP measurements of sample number 2 are well reproduced in the range of temperatures from $30^{\circ} \mathrm{C}$ to $300^{\circ} \mathrm{C}$ in the first cycle and during the heating of the second cycle. The TPP values measured in the beginning and end of the first cycle of heating differ in value not more than 3\% for thermal diffusivity and heat capacity and not more than $5 \%$ for heat conductivity.

Thermophysical properties deviation became more significant after heating up to $400^{\circ} \mathrm{C}$. The thermal diffusivity values have changed first of all. Thus, at the temperature of $100^{\circ} \mathrm{C}$ the thermal diffusivity became $8 \%$ lower during the control measurement of the second cycle, heat capacity was increased on $4 \%$, and heat conductivity was decreased on $6 \%$. 
TABLE 6: TPP values of the samples for $\mathrm{UO}_{2}$ samples series.

\begin{tabular}{|c|c|c|c|c|}
\hline \multirow{2}{*}{ Sample } & \multirow{2}{*}{ Temperature, ${ }^{\circ} \mathrm{C}$} & \multicolumn{3}{|c|}{ TPP coefficients } \\
\hline & & $a, \cdot 10^{-6} \mathrm{~m}^{2} / \mathrm{sec}$ & $C_{p}, J /(\mathrm{kg} \cdot \mathrm{K})$ & $\lambda, \mathrm{W} /(\mathrm{m} \mathrm{K})$ \\
\hline $\mathrm{UO}_{2}(95 \%)$ & 27 & 3.08 & 237 & 7.59 \\
\hline $\mathrm{UO}_{2}$ inside the chamber & 28 & 2.413 & 269 & 6.69 \\
\hline
\end{tabular}

TABLE 7: Results of determining correction coefficients.

\begin{tabular}{lccc}
\hline Sample & $K_{a}$ & $K_{c}$ & $K_{\lambda}$ \\
\hline Inside the chamber & $1.296 \pm 0.005$ & $0.893 \pm 0.008$ & $1.17 \pm 0.012$ \\
\hline
\end{tabular}

TABLE 8: Results of temperature changes of sample number 1 TPP coefficients measurement.

\begin{tabular}{|c|c|c|c|c|c|}
\hline \multirow{2}{*}{ Control measurements } & \multirow{2}{*}{ Temperature, ${ }^{\circ} \mathrm{C}$} & \multirow{2}{*}{ Pulse energy, J } & \multicolumn{3}{|c|}{ TPP coefficients } \\
\hline & & & $a, \cdot 10^{-6} \mathrm{~m}^{2} / \mathrm{sec}$ & $C_{p}, \mathrm{~J} /(\mathrm{kg} \cdot \mathrm{K})$ & $\lambda, \mathrm{W} /(\mathrm{m} \cdot \mathrm{K})$ \\
\hline \multicolumn{6}{|c|}{ 1st cycle, heating } \\
\hline 1 & $30.7 \pm 0.7$ & $13.52 \pm 0.05$ & $2.686 \pm 0.005$ & $228.4 \pm 0.7$ & $6.22 \pm 0.03$ \\
\hline 2 & $112.4 \pm 0.4$ & $13.01 \pm 0.08$ & $2.41 \pm 0.021$ & $253 \pm 1.2$ & $6.19 \pm 0.03$ \\
\hline 3 & $160 \pm 1.1$ & $12.79 \pm 0.05$ & $2.28 \pm 0.018$ & $270 \pm 3.0$ & $6.2 \pm 0.11$ \\
\hline 4 & $197.3 \pm 0.5$ & $12.73 \pm 0.09$ & $2.152 \pm 0.004$ & $281 \pm 1.9$ & $6.13 \pm 0.03$ \\
\hline 5 & $246.1 \pm 0.3$ & $12.48 \pm 0.04$ & $1.997 \pm 0.006$ & $291 \pm 1.4$ & $5.90 \pm 0.05$ \\
\hline 6 & $247.9 \pm 0.7$ & $16.36 \pm 0.08$ & $2.01 \pm 0.04$ & $292.2 \pm 0.5$ & $6.0 \pm 0.12$ \\
\hline 7 & $306.8 \pm 1.1$ & $16.1 \pm 0.13$ & $1.90 \pm 0.04$ & $307.0 \pm 0.3$ & $5.9 \pm 0.13$ \\
\hline \multicolumn{6}{|c|}{ 1st cycle, cooling } \\
\hline 8 & $259.8 \pm 0.4$ & $16.18 \pm 0.04$ & $1.953 \pm 0.006$ & $296 \pm 2.5$ & $5.86 \pm 0.07$ \\
\hline 9 & $205.1 \pm 0.4$ & $12.58 \pm 0.02$ & $2.09 \pm 0.013$ & $286 \pm 1.3$ & $6.08 \pm 0.05$ \\
\hline 10 & $67.8 \pm 0.7$ & $12.8 \pm 0.12$ & $2.516 \pm 0.007$ & $244 \pm 1.2$ & $6.22 \pm 0.03$ \\
\hline \multicolumn{6}{|c|}{ 2nd cycle, heating } \\
\hline 1 & $68.0 \pm 0.7$ & $13.03 \pm 0.02$ & $2.51 \pm 0.011$ & $246 \pm 2.5$ & $6.24 \pm 0.09$ \\
\hline 2 & $96.2 \pm 0.6$ & $12.76 \pm 0.05$ & $2.44 \pm 0.027$ & $256 \pm 1.4$ & $6.33 \pm 0.09$ \\
\hline 3 & $197.0 \pm 0.8$ & $12.59 \pm 0.08$ & $2.110 \pm 0.004$ & $286.3 \pm 0.8$ & $6.12 \pm 0.01$ \\
\hline 4 & $304.0 \pm 0.6$ & $16.26 \pm 0.02$ & $1.844 \pm 0.007$ & $308 \pm 1.8$ & $5.76 \pm 0.05$ \\
\hline 5 & $349 \pm 1.2$ & $15.98 \pm 0.03$ & $1.758 \pm 0.007$ & $319 \pm 2.6$ & $5.68 \pm 0.02$ \\
\hline 6 & $399.5 \pm 0.5$ & $15.97 \pm 0.05$ & $1.638 \pm 0.003$ & $326 \pm 1.4$ & $5.42 \pm 0.02$ \\
\hline \multicolumn{6}{|c|}{ 2nd cycle, cooling } \\
\hline 7 & $346.4 \pm 0.7$ & $15.98 \pm 0.03$ & $1.713 \pm 0.008$ & $322 \pm 3.1$ & $5.59 \pm 0.03$ \\
\hline 8 & $253 \pm 1.6$ & $16.57 \pm 0.04$ & $1.889 \pm 0.006$ & $297 \pm 3.0$ & $6.27 \pm 0.07$ \\
\hline 9 & $143.2 \pm 0.4$ & $13.04 \pm 0.09$ & $2.128 \pm 0.003$ & $279.9 \pm 0.2$ & $6.04 \pm 0.01$ \\
\hline 10 & $21.1 \pm 0.4$ & $13.20 \pm 0.04$ & $2.513 \pm 0.009$ & $237.7 \pm 0.4$ & $6.05 \pm 0.02$ \\
\hline \multicolumn{6}{|c|}{ 3rd cycle, heating } \\
\hline 1 & $68.0 \pm 0.7$ & $13.03 \pm 0.02$ & $2.51 \pm 0.011$ & $246 \pm 2.5$ & $6.24 \pm 0.09$ \\
\hline 2 & $96.2 \pm 0.6$ & $12.76 \pm 0.05$ & $2.44 \pm 0.027$ & $256 \pm 1.4$ & $6.33 \pm 0.09$ \\
\hline 3 & $197.0 \pm 0.8$ & $12.59 \pm 0.08$ & $2.110 \pm 0.004$ & $286.3 \pm 0.8$ & $6.12 \pm 0.01$ \\
\hline 4 & $304.0 \pm 0.6$ & $16.26 \pm 0.02$ & $1.844 \pm 0.007$ & $308 \pm 1.8$ & $5.76 \pm 0.05$ \\
\hline 5 & $349 \pm 1.2$ & $15.98 \pm 0.03$ & $1.758 \pm 0.007$ & $319 \pm 2.6$ & $5.68 \pm 0.02$ \\
\hline 6 & $399.5 \pm 0.5$ & $15.97 \pm 0.05$ & $1.638 \pm 0.003$ & $326 \pm 1.4$ & $5.42 \pm 0.02$ \\
\hline \multicolumn{6}{|c|}{ 3rd cycle, cooling } \\
\hline 7 & $346.4 \pm 0.7$ & $15.98 \pm 0.03$ & $1.713 \pm 0.008$ & $322 \pm 3.2$ & $5.59 \pm 0.03$ \\
\hline 8 & $253 \pm 1.6$ & $16.57 \pm 0.04$ & $1.889 \pm 0.006$ & $297 \pm 3.3$ & $6.27 \pm 0.07$ \\
\hline 9 & $182.2 \pm 0.4$ & $13.04 \pm 0.09$ & $2.128 \pm 0.003$ & $279.9 \pm 0.2$ & $6.04 \pm 0.01$ \\
\hline
\end{tabular}


TABLE 9: The results of TPP measurements of corium sample number 2 within the temperature range from $30^{\circ} \mathrm{C}$ to $400^{\circ} \mathrm{C}$.

\begin{tabular}{|c|c|c|c|c|c|}
\hline \multirow{2}{*}{ Control measurements } & \multirow{2}{*}{ Temperature, ${ }^{\circ} \mathrm{C}$} & \multirow{2}{*}{ Pulse energy, J } & \multicolumn{3}{|c|}{ TPP coefficient } \\
\hline & & & $a, \cdot 10^{-6} \mathrm{~m}^{2} / \mathrm{sec}$ & $C_{p}, \mathrm{~J} /(\mathrm{kg} \cdot \mathrm{K})$ & $\lambda, \mathrm{W} /(\mathrm{m} \cdot \mathrm{K})$ \\
\hline \multicolumn{6}{|c|}{ 1st cycle, heating } \\
\hline 1 & $28.2 \pm 0.2$ & $13.96 \pm 0.09$ & $2.773 \pm 0.004$ & $239.2 \pm 0.5$ & $6.822 \pm 0.004$ \\
\hline 2 & $52.1 \pm 0.2$ & $13.08 \pm 0.02$ & $2.73 \pm 0.012$ & $243.6 \pm 0.6$ & $6.85 \pm 0.04$ \\
\hline 3 & $108.5 \pm 0.9$ & $12.67 \pm 0.09$ & $2.524 \pm 0.009$ & $252.9 \pm 0.9$ & $6.57 \pm 0.05$ \\
\hline 4 & $154 \pm 1.7$ & $12.2 \pm 0.19$ & $2.385 \pm 0.005$ & $266 \pm 1.2$ & $6.53 \pm 0.019$ \\
\hline 5 & $207.0 \pm 0.6$ & $12.15 \pm 0.02$ & $2.221 \pm 0.005$ & $281 \pm 3.3$ & $6.43 \pm 0.08$ \\
\hline 6 & $206 \pm 1.0$ & $15.00 \pm 0.09$ & $2.21 \pm 0.012$ & $284 \pm 1.5$ & $6.44 \pm 0.06$ \\
\hline 7 & $253.5 \pm 0.9$ & $15.1 \pm 0.31$ & $2.06 \pm 0.013$ & $288.9 \pm 0.1$ & $6.12 \pm 0.04$ \\
\hline 8 & $304.6 \pm 0.8$ & $14.9 \pm 0.12$ & $1.93 \pm 0.010$ & $301 \pm 3.2$ & $5.99 \pm 0.06$ \\
\hline \multicolumn{6}{|c|}{ 1st cycle, cooling } \\
\hline 9 & $205 \pm 1.2$ & $15.57 \pm 0.08$ & $2.15 \pm 0.011$ & $284.1 \pm 0.9$ & $6.27 \pm 0.05$ \\
\hline 10 & $150.7 \pm 0.10$ & $13.17 \pm 0.04$ & $2.34 \pm 0.011$ & $276 \pm 1.1$ & $6.65 \pm 0.05$ \\
\hline 11 & $149.90 \pm 0.04$ & $16.09 \pm 0.03$ & $2.33 \pm 0.052$ & $271.1 \pm 0.4$ & $6.50 \pm 0.02$ \\
\hline 12 & $102.8 \pm 0.3$ & $12.87 \pm 0.08$ & $2.514 \pm 0.008$ & $256 \pm 1.8$ & $6.63 \pm 0.06$ \\
\hline \multicolumn{6}{|c|}{ 2nd cycle, heating } \\
\hline 1 & $33.9 \pm 0.9$ & $13.58 \pm 0.06$ & $2.768 \pm 0.006$ & $235 \pm 1.5$ & $6.68 \pm 0.03$ \\
\hline 2 & $99 \pm 1.1$ & $13.75 \pm 0.05$ & $2.51 \pm 0.016$ & $258 \pm 2.4$ & $6.67 \pm 0.05$ \\
\hline 3 & $211 \pm 2.0$ & $13.52 \pm 0.08$ & $2.174 \pm 0.001$ & $286 \pm 3.0$ & $6.40 \pm 0.07$ \\
\hline 4 & $297 \pm 2.2$ & $13.15 \pm 0.04$ & $1.953 \pm 0.005$ & $300 \pm 2.1$ & $6.03 \pm 0.04$ \\
\hline 5 & $293.4 \pm 0.6$ & $16.20 \pm 0.03$ & $1.944 \pm 0.009$ & $299 \pm 1.3$ & $5.98 \pm 0.05$ \\
\hline 6 & $341.8 \pm 0.1$ & $15.97 \pm 0.05$ & $1.850 \pm 0.006$ & $308.5 \pm 0.5$ & $5.87 \pm 0.02$ \\
\hline 7 & $400 \pm 1.7$ & $15.5 \pm 0.10$ & $1.700 \pm 0.004$ & $316 \pm 2.2$ & $5.53 \pm 0.02$ \\
\hline \multicolumn{6}{|c|}{ 2nd cycle, cooling } \\
\hline 8 & $299.1 \pm 0.3$ & $15.91 \pm 0.09$ & $1.877 \pm 0.007$ & $305 \pm 1.3$ & $5.88 \pm 0.04$ \\
\hline 9 & $202.6 \pm 0.2$ & $16.1 \pm 0.12$ & $2.07 \pm 0.013$ & $294 \pm 1.6$ & $6.27 \pm 0.07$ \\
\hline 10 & $202.2 \pm 0.3$ & $13.1 \pm 0.13$ & $2.082 \pm 0.007$ & $293 \pm 3.0$ & $6.28 \pm 0.08$ \\
\hline 11 & $103 \pm 1.6$ & $13.75 \pm 0.04$ & $2.345 \pm 0.007$ & $262 \pm 3.4$ & $6.32 \pm 0.07$ \\
\hline 12 & $42.5 \pm 0.4$ & $13.37 \pm 0.08$ & $2.58 \pm 0.016$ & $245 \pm 1.7$ & $6.50 \pm 0.08$ \\
\hline
\end{tabular}

Results of TPP measuring of both corium samples have revealed the changing of thermal diffusivity and heat conductivity values after heating up to $400^{\circ} \mathrm{C}$ cycle. Here we should take into account the fact that the sample actual temperature could get higher temperatures especially from the side surfaces reacting on the temperature of the heating chamber walls.

Figure 6 shows the results of measuring TPP coefficients of the full-scale corium samples comparing with the results of calibration measurements of the uranium dioxide. Character of the obtained temperature dependencies of TPP coefficients coincides with the temperature dependencies obtained for uranium dioxide.

The heat capacity and temperature dependence of samples heat capacity coincide within the range of 3\% for both, the corium samples and uranium dioxide samples.

Heat conduction and thermal diffusivity of the corium samples differ most, they are 10-15\% lower than those of the uranium dioxide.

TPP fixed changes after heating up to $400^{\circ} \mathrm{C}$ made the same $5-10 \%$ for the thermal diffusivity. Supposing that the difference of the material samples thermal diffusivity from the thermal diffusivity of the sintered uranium dioxide is mainly determined by the porosity and fracture we can suppose that the fracture parameters had to be changed significantly (two times approximately) for obtaining the similar effect.

Measuring the samples geometric dimensions and mass has not revealed these parameters registered changes in the experiment result.

\section{Conclusion}

We have studied thermophysical properties of full-scale corium of the fast energy reactor obtained during the experiment on the IGR research reactor. Using the got results we have come to the following conclusions:

(1) Experimental data on TPP samples of full-scale corium of fast reactor in the temperature range from $30^{\circ} \mathrm{C}$ to $\sim 400^{\circ} \mathrm{C}$ was obtained for the first time.

(2) Well reproducibility of results was shown in the temperature range from $30^{\circ} \mathrm{C}$ to $300^{\circ} \mathrm{C}$.

(3) Character of obtained temperature dependence of TPP sample coefficient of full-scale corium coincides with character temperature dependence, obtained for sintered uranium dioxide samples. 


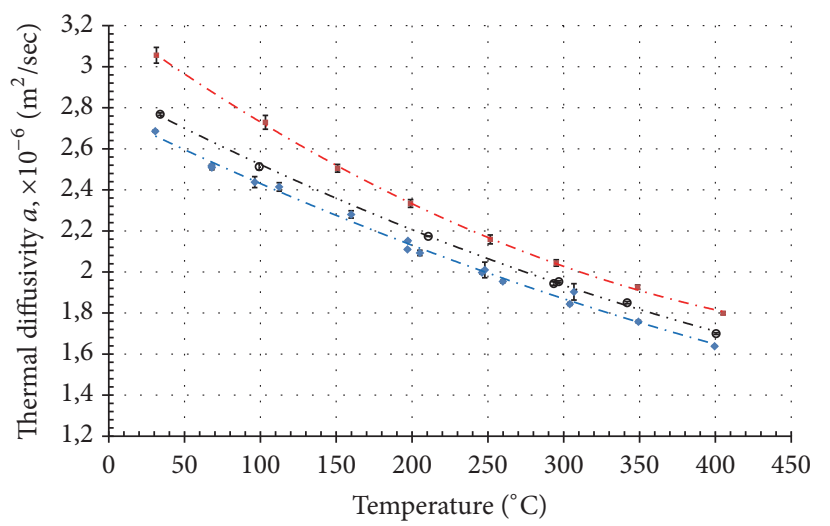

- No. 1

- No. 2

- $\mathrm{UO}_{2}$

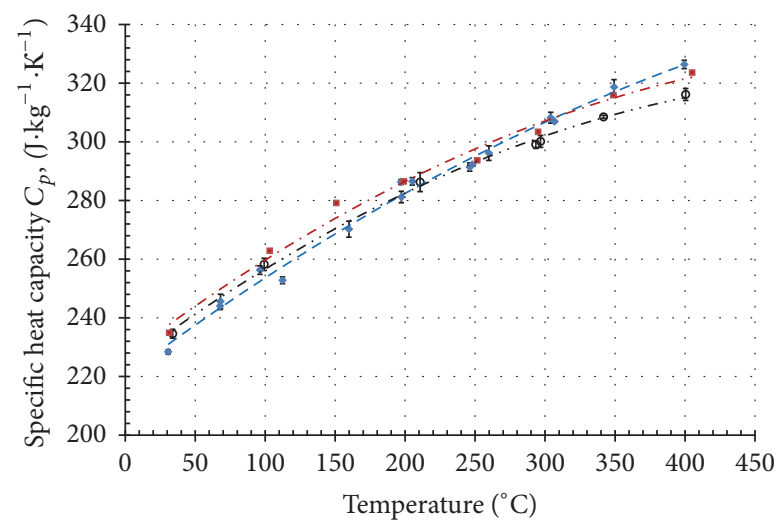

- No. 1

- No. 2

- $\mathrm{UO}_{2}$

(a)

(b)

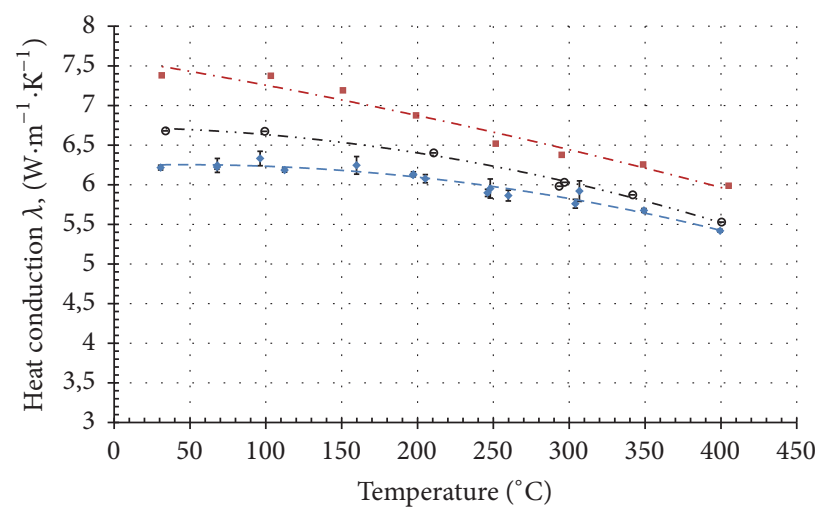

- No. 1

- No. 2

- $\mathrm{UO}_{2}$

(c)

FIGURE 6: Comparing the results of TPP measuring of full-scale corium and sintered uranium dioxide samples.

\section{Conflicts of Interest}

The authors declare that there are no conflicts of interest regarding the publication of this paper.

\section{Acknowledgments}

The work is supported by the Ministry of Education and Science of the Republic of Kazakhstan as a funded grant project "Investigation of Thermal-Physical Properties of Fast Reactor Core Melting" (Contract no. 271 on 12.02.2015).

\section{References}

[1] J. K. Fink, "Thermophysical properties of uranium dioxide," Journal of Nuclear Materials, vol. 279, no. 1, pp. 1-18, 2000.

[2] M. Skakov, N. Mukhamedov, I. Deryavko et al., "Temperature dependence of thermophysical properties of light-water reactor prototype corium," in Proceedings of the International Conference on, Materials and Engineering and Industrial Applications (MEIA '15), pp. 75-79, Hong Kong, September 2015.
[3] D. E. Burkes, C. A. Papesch, A. P. Maddison, T. Hartmann, and F. J. Rice, "Thermo-physical properties of DU-10 wt.\% Mo alloys," Journal of Nuclear Materials, vol. 403, no. 1-3, pp. 160-166, 2010.

[4] M. Skakov, N. Mukhamedov, W. Wieleba, and I. Deryavko, "Study of corium thermophysical properties of light water reactor with different oxidation degrees of zirconium, Research Journal of Pharmaceutical," Research Journal of Pharmaceutical, Biological and Chemical Sciences, vol. 7, no. 4, pp. 2018-2024, 2016.

[5] V. Zhdanov, V. Baklanov, V. Sabluk et al., "The Methodology of Determining Heat-Transfer Properties of the Samples of Promising Fuel for Water-Moderated Water-Cooled Power Reactor," in Proceedings of the International Conference on Nuclear Power of the Republic of Kazakhstan, pp. 150-156, Institute of Atomic Energy of National Nuclear Center RK (IAE NNC RK), Kurchatov, Kazakhstan, 2008.

[6] Thermophysical properties database of materials for light water reactors and heavy water reactors, The IAEA, Wien, Austria, June 2006. 


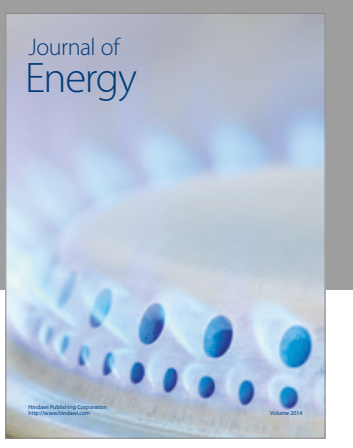

Journal of

Industrial Engineering
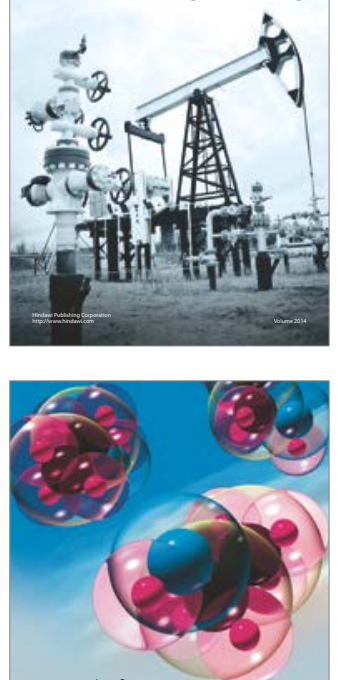

Fuels
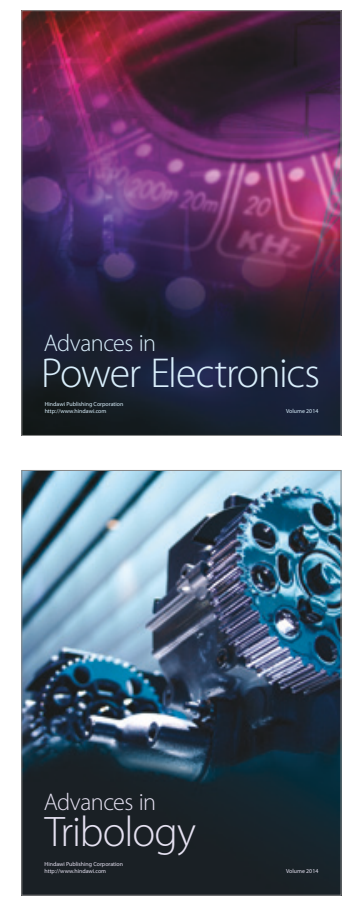
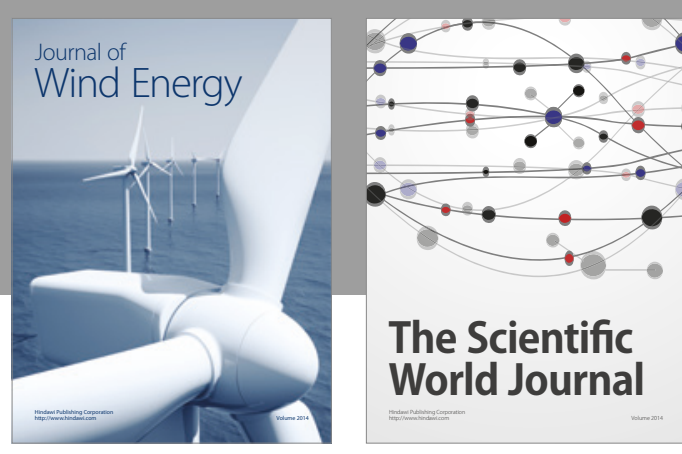

The Scientific World Journal
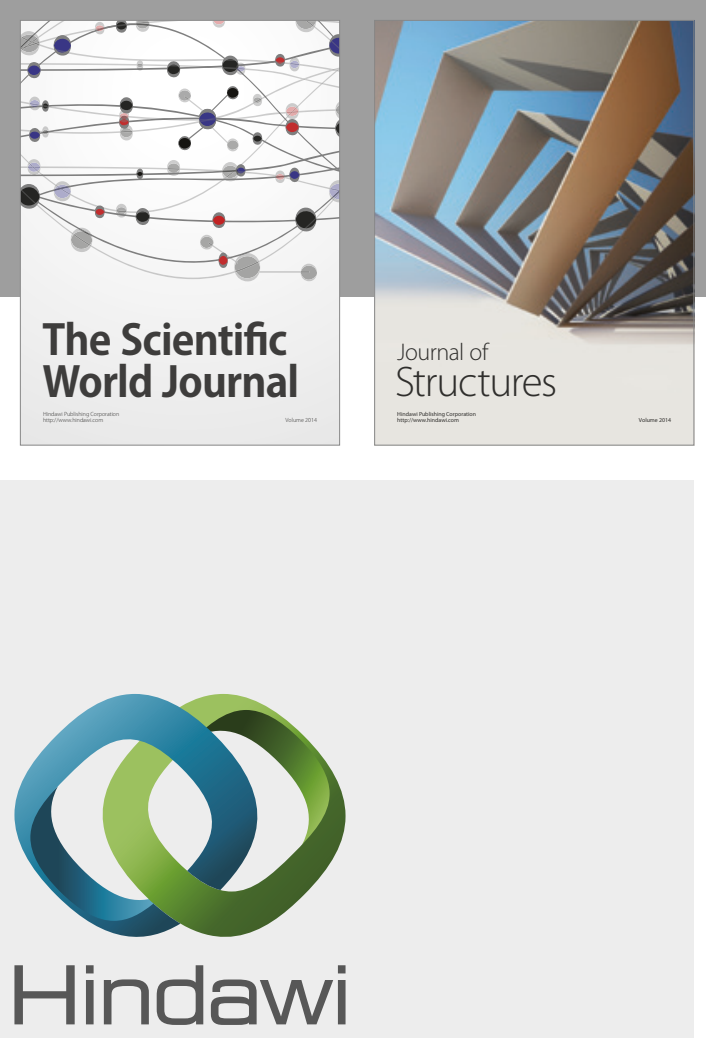

Submit your manuscripts at

https://www.hindawi.com
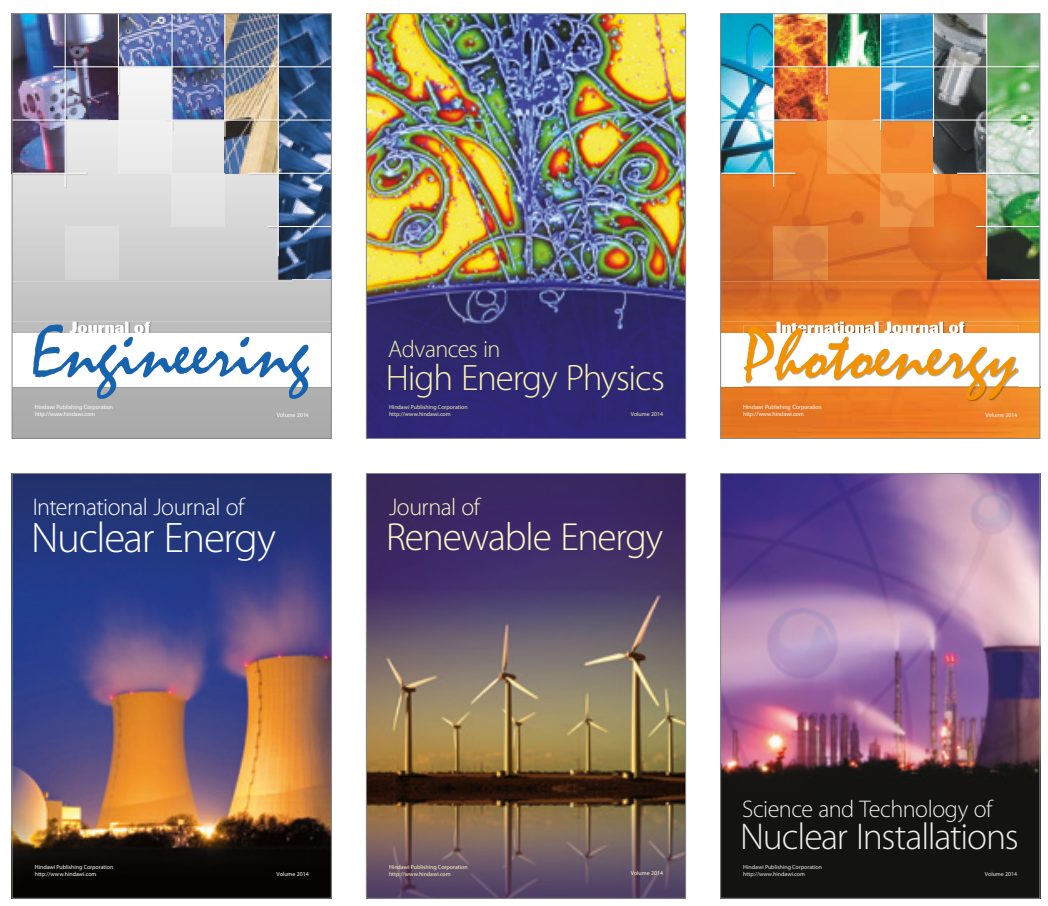

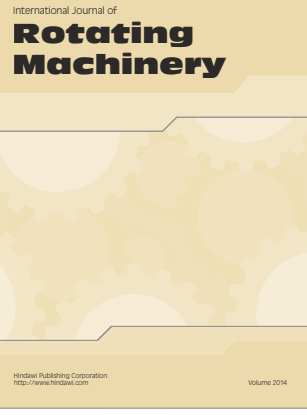

Journal of

Petroleum Engineering

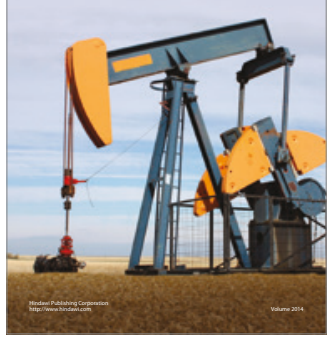

Journal of
Solar Energy
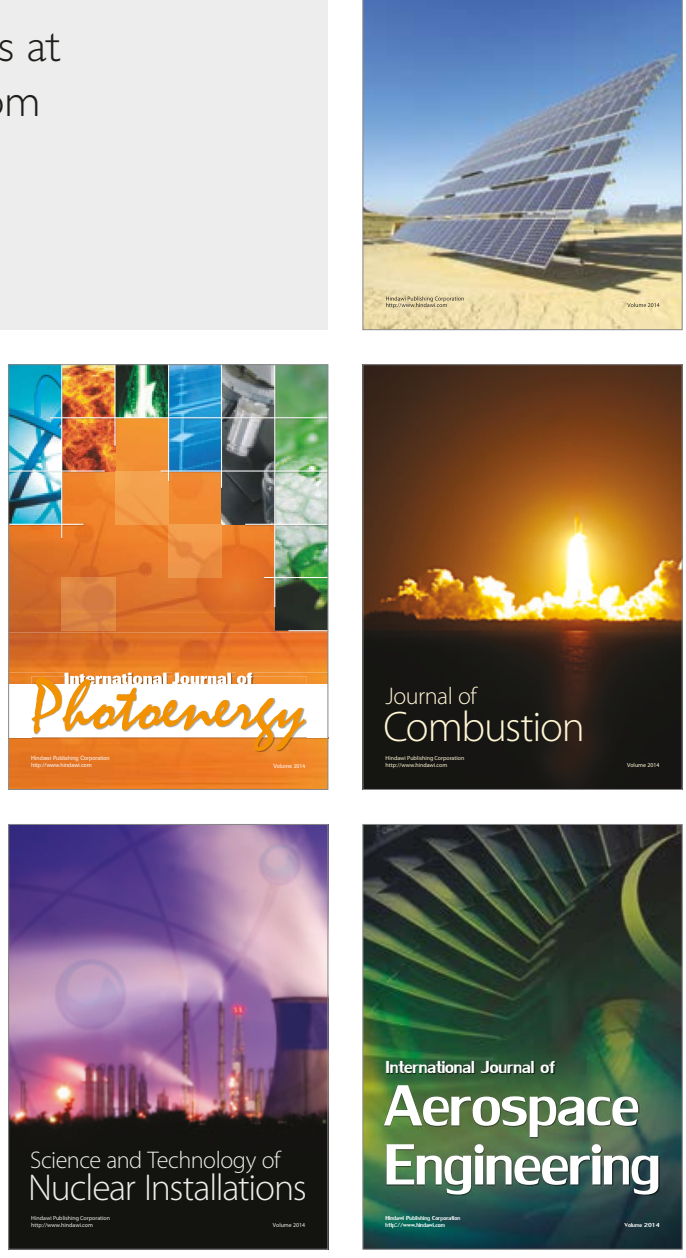